\title{
Hibridación, interacción social y adaptación cultural en la Costa de Mosquitos, siglos XVII y XVIII
}

\author{
Claudia García
}

Universidad de Uppsala

A partir de su emergencia como grupo socialmente diferenciado a fines del siglo XVII los indios miskitu transformaron su cultura por medio de procesos profundamente influenciados por la interacción con el Otro, por sus ideas y por sus prácticas. Y el grupo, al tiempo que asimilaba a individuos de diferente procedencia étnica, incorporaba objetos materiales que se convirtirían en necesidades culturales nuevas. La intención de este trabajo es relacionar la conducta social de los miskitu durante los siglos XVII y XVIII con su interés por obtener productos no tradicionales.

PALABRAS CLAVE: Hibridación, etnogénesis, grupo étnico, adaptación cultural, interacción social, indios miskitu, zambos miskitu, Costa de Mosquitos, Nicaragua.

From their emergence as a socially differentiated group at the end of the 17th Century, the Miskitu Indians transformed their culture through processes which were profoundly influenced by their interaction with Others, by their ideas and their customs. And, whilst assimilating into the group individuals of different ethnic origins, they also incorporated material objects which would subsequently become new cultural requirements. The aim of this project is to relate the social behaviour of the Miskitu during the 17th and 18th Centuries to their interest in obtaining non-traditional products.

KEYwords: Hybridation, ethnogenesis, ethnic group, cultural adaptation, social interaction, Miskitu Indians, Miskitu Zambos, Mosquito Coast, Nicaragua.

\section{Introducción}

La mayoría de los autores concuerda en señalar que la etnogénesis de los miskitu es el resultado de la hibridación social y cultural entre los indios bahwika (un subgrupo de indios mayangnas), africanos y europeos a mediados del siglo XVII. ${ }^{1}$ En unos escritos españoles del siglo XVIII se identifica a los miskitu como "una clase de zambos compuesta de pocos indios puros, de algunos blancos y mulatos forajidos, y de mestizos de negro e indiano." En esta cita se pone de relieve el origen confuso de los miskitu, por lo que su

1 M.W.: The Mosqueto Indians and his Golden River; Being a familiar description of the Mosqueto Kingdom in America, A Collection of Voyages and Travels, J. Walthoe, London, 1699, pág. 307.

2 Biblioteca Nacional, Madrid, Papeles Varios relativos a la América Central, 17619, 11, 92, "Modo de restaurar la Costa de Mosquitos", anónimo, sin fecha. 
existencia no puede interpretarse más que como una transgresión a la sociedad colonial. No sólo porque en sí el mestizaje implica ambivalencia y ambigüedad (carácter híbrido), a la vez que anomalía (pertenencia simultánea a dos mundos), sino también porque la identificación de los miskitu como los descendientes de "blancos y mulatos forajidos" implica que se los considera gentes "sin Dios ni ley". Poblaciones de estas características se localizan en las fronteras de los dominios coloniales del Nuevo Mundo.

El territorio de la Costa de Mosquitos (la Tologalpa y la Taguzgalpa) abarca lo que actualmente corresponde a las dos Regiones Autónomas (del Atlántico Norte y Sur) y parte de los departamentos de Río San Juan, Chontales, Boaco, Matagalpa, Jinotega y Nueva Segovia, en Nicaragua, y la franja costera que llega al Cabo Camerón, en Honduras. Una frontera natural, las Sierras Centrales, separa la zona de influencia española de la Costa de Mosquitos, donde habitan tribus semi-nómadas de cazadores y recolectores. El rechazo de las poblaciones de los indios caribes (jicaques, payas y chatos) que residen en la franja central del país frena el avance de la colonización española hacia el Este, y permite a la Costa de Mosquitos y a sus habitantes mantenerse autónomos. Pero la ausencia de población española posibilitará la llegada de otros actores sociales (europeos y africanos).

El estudio de las fronteras pone de relieve la diversidad de relaciones que la interacción entre grupos culturalmente distintos origina. ${ }^{3}$ Por eso parto de considerar a la Costa de Mosquitos como una "zona de contacto" en la que la interacción social, económica y militar entre los diferentes actores sociales está gobernada por reglas más flexibles que en las zonas integradas al dominio colonial. ${ }^{4} \mathrm{El}$ proceso de adaptación entre los grupos sociales se da por medio de ajustes estructurales, matizados tanto por entendimientos como por desentendimientos, así como por la aparición de nuevas áreas (comunes) de acción social, nuevos valores y prácticas. ${ }^{5}$

3 Helms, Mary: "Introduction" en Helms, Mary y Loveland Franklin (eds.): Frontier Adaptations in Lower Central America, ISHI, Philadelphia, 1976, pág. 2. La frontera puede ser considerada un lugar geográfico, un proceso social o una situación, consultar: Wyman, Walker y Clifson B. Kroeber: The Frontier in Perspective, University of Wiscosin Press, Madison, 1957. Véase también David J. Weber: The Spanish Frontier in North America, Yale University Press, New York, 1992.

4 Me baso aquí en la definición de frontera de Dauton, Martin y Halpern, Rick: "Introduction: British Identities, Indigenous Peoples, and the Empire" en Daunton, Martin, y Halpern, Rick (eds.): Empire and Others. British Encounters with Indigenous Peoples 1600-1850, UCL Press, London, 1999, pág. 3.

5 Es pertinente aquí definir al "middle-ground" como "the place in between, in between cultures, peoples, and in between empires and the non state world of villages." Consultar White, Richard: The Middle Ground. Indians, Empires and Republics in the Great Lake Region 1650-1815, University Press, Cambridge, 1991, pág. 17. 


\section{Los ingleses}

Entre los primeros ingleses que se acercan a la región hay que dedicar una mención especial a la compañía de Providencia (1630-1641), porque sienta la base para las futuras relaciones entre la Costa de Mosquitos e Inglaterra. Esta compañía la forman prominentes puritanos, miembros del Parlamento, como el conde de Warwick. En 1630, luego de que el almirantazgo aprobara su constitución, la compañía se establece en la isla de Providencia, frente a la Costa de Mosquitos. ${ }^{6}$ Esta isla recibe asiduas visitas de piratas holandeses, entre los que hay que nombrar a Abraham Blauveldt, quien será una figura clave para facilitar los contactos entre los recién llegados y los indios de tierra firme, con quienes el holandés mantiene buenas relaciones. ${ }^{7}$

La compañía se propone intercambiar productos locales por otros de manufactura europea y trabajar la tierra. ${ }^{8}$ Sin embargo el cultivo del algodón y el tabaco, al que los puritanos se abocan, luego de importar 400 esclavos, no resulta todo lo exitoso que esperaban. A esto se debe que el comercio pase a ser la actividad más importante. Con este fin, y gracias a la ayuda que les presta Blauveldt, la compañía se establece en 1631 entre los indios de Cabo Gracias a Dios. Los ingleses intercambian con los indios cuentas de vidrio, cuchillos, armas de fuego, hachas y otros productos de manufactura inglesa por plumas de colores, pieles, goma de pino, azúcar de caña, lino, carey y zarzaparrilla (conocida por su probada eficiencia para curar la escrófula, la elefantiasis y las enfermedades venéreas). ${ }^{9}$

En 1632, y para afianzar la relación con los indios del lugar, los colonos ingleses invitan al hijo del jefe principal de los miskitu a Inglaterra. Junto con él se envía uno de los primeros cargamentos de productos locales, entre los que hay que destacar las hierbas medicinales y la fibra de lino o seda, que en Londres será conocida como la "hierba de Camock". El joven miskitu permanece tres años en Inglaterra como huésped del conde

6 Esta isla, descubierta alrededor de 1527 por los españoles y nombrada como Santa Catalina, no contaba con ningún asentamiento español.

7 Abraham Blauveldt fundó el primer establecimiento europeo fijo en la Costa del Atlántico de Nicaragua, al que se conoce con el nombre de Bluefields, nombre que es traducción inglesa de Blauveldt.

8 Ordahl Kupperman, Karen: The Providence Island 1630-1641. The Other Puritan Colony, University Press, Cambridge, 1993, pág. 166.

9 Romero Vargas, Germán: Las sociedades del Atlántico de Nicaragua en los siglos XVII y XVIII, Banco Nicaragüense, Managua, 1988, pág. 23. 
de Warwick; de regreso en la Costa de Mosquitos, al ocupar el lugar de su padre con el nombre de Oldman I, jura lealtad al rey de Inglaterra.

Durante la corta vida de la compañía de Providencia se suceden las contravenciones de los colonos a las disposiciones dictadas por la dirección. Una de ellas, a la que inevitablemente hay que referirse por la importancia que asumirá en el futuro, es la prohibición de entregar armas a los indios. Las armas son, sin embargo, uno de los productos más populares a intercambiar con los miskitu y su adquisición va a transformar la dinámica de las relaciones entre los diferentes grupos que habitan la región. Los miskitu comienzan a atacar a las demás poblaciones de indios para hacer cautivos y venderlos a los ingleses como esclavos. Son las armas, también, las que los convierten en los aliados militares de los ingleses en América Central. Fuerzas conjuntas de ingleses y miskitu van a atacar a los poblados españoles del territorio de América Central hasta finales del siglo XVIII.

No se considera adecuado que los colonos de Providencia establezcan vínculos con las mujeres nativas así que, para que ello no suceda, no está permitida la entrada de mujeres a la isla. Pero muchos de los colonos son hombres solos, cuyas esposas se han negado a viajar al Nuevo Mundo, y se unen a las mujeres miskitu. ${ }^{10}$ Como estas uniones mixtas son frecuentes la dirección de la compañía tratará de legalizarlas, obligando a los colonos a asumir el compromiso de bautizar y educar en forma cristiana a los niños que nazcan. ${ }^{11}$

Cuando la isla de Providencia es recuperada por los españoles en 1641 algunos colonos van a optar por quedarse a vivir en la Costa de Mosquitos. La población europea que allí reside está formada por personas "sin ley", asentadas en forma dispersa y, en muchos casos, asimiladas a los nativos. Se trata de piratas, bucaneros y ex bucaneros de diferentes nacionalidades. M.W. menciona, por ejemplo, el fracaso por falta de provisiones de un asentamiento francés, probablemente de piratas, en la zona del litoral que se extiende entre el Cabo Gracias a Dios y Sandy-Bay. El holandés Abraham Blauveldt tiene también una base de operaciones en el litoral Sur del Atlántico. Y hay ex bucaneros británicos que, por tener cuentas pendientes con la justicia, están refugiados entre los miskitu. A modo de ejemplo menciona M.W. a un grupo de piratas ingleses que viven ocultos en las

10 Ibídem.

11 Sorsby, William: "Una compañía puritana en Mosquitia”, Nicaraguac, Managua 1982, pág 71 . 
cercanías del río Wanks (Coco) “como prófugos de la justicia." ${ }^{2}$ Y más allá, en la zona que se extiende entre las riberas del río Housey y las del río Bragman, otros tres ingleses conviven con algunas familias de indios. ${ }^{13}$ Uno de ellos es originario de Bristol y ha llegado luego de asesinar a un hombre en San Cristóbal, mientras que los otros dos se han quedado a vivir en la región después de participar en el ataque a Segovia para no ser juzgados por piratería en su tierra. ${ }^{14}$

Los piratas son grupos subalternos en su contexto de origen y, por lo tanto, representan una transgresión a los conceptos económicos elaborados por las clases medias como a las nociones domésticas de "realidad". ${ }^{15}$ No es de extrañar, entonces, que las reglas morales por las que se rige su conducta sean maleables y les permitan adaptarse en forma satisfactoria a la población nativa de acogida. Es indudable que el trato entre ambos es considerado equitativo por ambas partes para que así sea. Los piratas entregan a los indios productos no tradicionales que se convierten en necesidades culturales. Hay que señalar también la adquisición, por parte de los miskitu, de nuevas habilidades (como el manejo de las armas de fuego o el dominio del idioma inglés), así como la incorporación de nombres ingleses; nombres que los piratas escogen para ellos. ${ }^{16}$ Es ésta, por lo tanto, una forma de establecer vínculos con los ingleses, equiparable al compadrazgo.

Los miskitu corresponden a los ingleses con diversas prestaciones masculinas, por ejemplo, en las expediciones de piratería. ${ }^{17} \mathrm{Y}$ como, además, los miskitu son buenos marineros y excelentes pescadores de tortugas y manatíes, son ellos quienes se encargan de abastecer a los barcos piratas. $^{18}$

Los piratas reciben, asimismo, los servicios domésticos y sexuales de las mujeres miskitu y parece que en muchos casos adoptan la forma polígama de unión sexual/afectiva practicada por los jefes miskitu principales. Lo que, por otra parte, es bastante común entre los europeos que llegan a

12 M.W.: The Mosqueto Indians ..., pág. 305.

13 Ibídem, pág 51.

14 Ibídem, pág. 52.

15 Turtley, Hans: Rum, Sodomy and the Lash. Piracy, Sexuality, and Masculine Identity, University Press, New York, 1999, pág. 75.

16 M.W: The Mosqueto Indians..., pág. 307. pág. 34.

17 Exquemelin, Alexander: "Bucaneros en América" (1684), Nicaraguac, Managua, 1982,

18 Ibídem. Dampier, William: The Voyages of Captain William Dampier by Captain William Dampier, Hummingbird Press, London, 1908, vol. I, págs. 39-40, 61. 
otros lugares de las Indias Occidentales. ${ }^{19}$ Según el relato de M.W., hay ingleses que tienen a su servicio "cuarenta indios salvajes entre esclavos y prostitutas" con los que llevan "una vida de holgazanería y paganismo."’o Estas "prostitutas" son, seguramente, mujeres miskitu que mantienen relaciones sexual/afectivas con los ingleses.

Puede decirse, por lo tanto, que la voluntariedad a unirse con los europeos constituye una forma de adaptación a las relaciones coloniales y el factor decisivo que conlleva a que ambos grupos se fundan entre sí, transformando sus costumbres y sus representaciones culturales. ${ }^{21}$ Para fines del siglo XVII la presencia inglesa en la región comienza a cristalizar en una estructura comercial sólida, justificada por la existencia de un "reino amigo" con una dinastía hereditaria de reyes zambos miskitu. El nieto de aquel joven miskitu que visitó la corte inglesa, a instancias de la compañía de la isla de Providencia, es coronado como rey de la Costa de Mosquitos con el nombre de Jeremy I por el gobernador de Jamaica, en 1687. El área de influencia inglesa en el Caribe pasa así a tener una frontera territorial en tierra firme.

\section{Los africanos}

Un número indeterminado de africanos llega a la región en 1641. Algunos años después, un pirata se va a referir a los miskitu como un pueblo pequeño de unos mil setecientos habitantes entre los cuales viven algunos africanos llegados a nado, cuando el barco en el que viajan naufraga frente a la costa, luego de que los africanos se amotinaran y mataran a la tripulación con el propósito de regresar a Africa. ${ }^{22} \mathrm{Al}$ parecer, estos africanos tocan tierra firme, por primera vez, en unas islas pequeñas - los Cayos

19 Thompson, Vicent Bakpetu: The Making of the African Diaspora in the Americas 14411900, Harlow, Longman, 1987.

20 Ibídem.

21 García, Claudia: "Relaciones sexual/afectivas entre los miskitos en los siglos XVII y XVIII", Wani, Revista del Caribe Nicaragüense, 28, Managua, 2002, págs. 16-33.

22 Exquemelin: "Bucaneros...", pág. 34. Esta información es confirmada por la "Consulta de Don Francisco Campo de Arve al Consejo de Indias, del 8 de julio de 1739" en De Peralta, Manuel: Costa Rica, Costa de Mosquitos. Documentos para la historia de la jurisdicción territorial de Costa Rica y de Colombia, París, 1898, pág 57. Y por un informe español: "Informe del Licenciado Don Ambrosio Thomás Santaella Melgarejo, Guatemala 3 de abril de 1715”, ibídem, pág. 78. 
Mosquitos - y desde allí se dirigen a tierra firme. ${ }^{23}$ Otra fuente española fija en 1650 la fecha del naufragio del barco negrero, y afirma que éste es portugués. ${ }^{24}$ Mientras que una tercera fuente señala que en 1652 se pierde una nave inglesa, cargada de africanos, frente a la Costa de Cabo Gracias a Dios y que dichos africanos se quedan a vivir entre los indios. ${ }^{25} \mathrm{Y}$ agrega: "en ese tiempo contentábanse (los africanos) con vivir bárbaramente entre aquellos gentiles sin aspirar a otra cosa y creciendo su número con la procreación que resultaba de las indias que atraían.”26

En base a otras fuentes del siglo XVIII, Ordahl Kupperman sugiere que estos africanos son los que han escapado de la isla de Providencia al caer ésta en manos de los españoles. ${ }^{27}$ Las fechas concuerdan, ya que es en el mismo año, 1641, que los españoles ocupan Providencia y que se registra la llegada de los africanos a la Costa de Mosquitos. Ordahl Kupperman indica, además, que los españoles encuentran en la isla un número menor de esclavos del que era de esperar. ${ }^{28}$ No es extraño que algunos africanos hubieran seguido al contingente de colonos puritanos que busca refugio en la Costa de Mosquitos. Sin embargo, me inclino a pensar que puede tratarse de dos flujos de africanos diferentes: uno proveniente de la isla de Providencia y otro del naufragio del barco negrero.

Se afirma que estos africanos, una vez que llegan a tierra firme, se enfrentan con los indios caribes que allí habitan y, finalmente, logran vencerlos. Así que "con las mujeres de los vencidos se fueron multiplicando los vencedores y porque ya murieron aquellos primeros huéspedes, se llaman hoy sus descendientes zambos, hijos de negros e indias." ${ }^{29}$ Es posible que el proceso de hibridación se haya iniciado con un conflicto entre los

23 Este sería el origen del nombre de mosquitos con el que, posteriormente, se nombraría tanto a la región como a uno de sus habitantes. Para profundizar en la idea de toponimia convertida en gentilicio, consultar Romero Vargas: Las sociedades del ...., págs. 124-125. Otra posibilidad sería que la denominación de miskitu, cuya forma en las primeras fuentes era "mosqueto", "mosquito", "musketo", "mustique", se utilizara para denominar al grupo nativo que portaba mosquetes. A favor de esta última posibilidad se inclina, entre otros, Helms, Mary: Asang. Adaptaciones al contacto cultural en una sociedad misquito, México, 1976, pág. 9.

24 "Informe del Capitán General de Guatemala, Don Pedro de Rivera, del 23 de noviembre de 1742”, en De Peralta: Costa Rica y ..., pág. 121.

25 "Informe del Licenciado Don Ambrosio Thomás Santaella Melgarejo, Guatemala, 3 de abril de 1715 ", ibídem, pág. 78.

26 Ibídem.

27 Ordahl Kupperman: The Providence Island..., pág. 338.

28 Ibídem.

29 "Informe de Don Fray Benito Garrett y Arboli, Obispo de Nicaragua, sobre los mosquitos y el modo de reducirlos" en De Peralta: Costa Rica y ..., pág. 57. 
africanos y los indios, pero me inclino a considerar que fueron los indios los que vencieron a los africanos. Exquemelin observa durante su estancia en la región que los africanos han sido apresados por los indios y les sirven de esclavos. ${ }^{30}$

Con independencia a que esta migración de africanos pueda provenir de la isla de Providencia o del naufragio del barco negrero, se trata de individuos que huyen de la esclavitud. Por eso, llama la atención que los africanos no se rebelen al ser esclavizados por los indios. Una posible explicación puede ser que el carácter igualitario de la sociedad nativa permitiera a los africanos integrarse al grupo, con la obligación de contribuir a la subsistencia de una familia pero con la libertad de regirse según sus usos y costumbres. De ser así, y hay muchos indicios en este sentido, el concepto de esclavitud entre los miskitu se asemejaba al existente en ciertos lugares de Africa, sobre el que se conoce por el relato de un esclavo liberado. ${ }^{31}$

Una tesis reciente afirma, por el contrario, que los miskitu son conocidos ya a principios del siglo XVII como los indios guaianes, es decir "los indios que habitan el río Wangki —o Guani" (río Coco). ${ }^{32}$ De ser correcto que los nombrados como indios guainaes sean los mismos a los que más tarde se va a nombrar como miskitu, éstos se habrían mezclado con anterioridad con los españoles sobrevivientes de una expedición militar realizada a la región en $1609 .{ }^{33}$ No me resulta posible, en base al material del que dispongo, confirmar o refutar dicha hipótesis.

Cuando M.W. visita la región en 1699, o sea algunos años después de que lo hiciera Exquemelin, puede constatar que en la ribera izquierda del río Wanks (río Coco) reside un mulato llamado Capitán Kit, y en la ribera opuesta, Garret, "negro de Guinea africana" que llega huyendo...tras el naufragio del barco negrero frente a la Costa, "con varios mulatos y otros de diferentes castas", quienes lo reconocen como jefe. A veinte leguas de allí habita Patrick, otro mulato hermano de Kit. ${ }^{34} \mathrm{Y}$, un poco más lejos, hay "un caserío indígena de siete ranchos bajo el dominio de Patrick, o mejor

30 Exquemelin: "Piratas de...", pág. 35.

31 Equiano, Oladah: Equiano's Travels. His autobiography. The interesting Narrative of the Life of Oladah Equiano or Gustavus Vassa the African (1791), Heinemann, Oxford, 1996.

32 Offen, Karl Henry: The Miskitu Kingdom. Landscape and the Emergence of a Miskitu Ethnic Identity, Northeastern Nicaragua and Honduras, 1600-1800, UMI Microform 9947340, Texas, 1999, pág. 107.

33 Vázquez, Francisco: Crónica de la Provincia del Santísimo nombre de Jesús de Guatemala (1714), Tipografía Nacional, Guatemala, 1944, Tomo IV, pág. 79.

34 M.W: The Mosqueto Indians and..., pág. 307. 
dicho de su familia, pues todos allí son parientes". Y en este último lugar pueden contarse "cincuenta y dos hombres capaces de tomar las armas", entre indios y mulatos. ${ }^{35} \mathrm{Y}$, aunque la mayoría de ellos son de pelo lacio y piel bronceada, otros, por haberse mezclado con africanos, lo tienen rizado y son más oscuros. ${ }^{36}$

Un informe de las autoridades españolas de la provincia de Nicaragua, por su parte, menciona un ataque de "mulatos o sambos" y, aunque no se los nombra como miskitu, todo hace suponer que se trata de ellos. ${ }^{37}$ Recién en 1704 se relaciona en las fuentes españolas a los zambos que habitan en la zona de Cabo Gracias a Dios con las uniones mixtas de los africanos sobrevivientes de un naufragio, los indios caribes de tierra firme y los piratas ingleses. ${ }^{38}$ De este informe trasciende que a comienzos del siglo XVIII ya se identifica en los documentos españoles a los miskitu con una categoría diferente. A partir de entonces se van a suceder los comentarios acerca de que dichos "zambos o mulatos" se llaman "mosquitos". Para los españoles son los zambos o mulatos miskitu los que sobresalen en un primer momento, quizá por la estrecha relación que estos mantienen con los ingleses. O, tal vez, porque este asentamiento de zambos o mulatos rebeldes es similar a otros conformados por esclavos cimarrones en diferentes lugares fronterizos del Nuevo Mundo. ${ }^{39}$

Para fines del siglo XVII los africanos han sido asimilados a la sociedad de acogida localizada, especialmente, en la zona circundante a Cabo Gracias a Dios, en la que los valores y prácticas provenientes de Africa se van a fundir con los indígenas. ${ }^{40}$

El mestizaje con los africanos se suma al ya producido con los europeos, al que me he referido anteriormente, y conlleva en muchos casos al uso de denominaciones confusas para identificar a los miskitu. Por lo general, se nombra como indios puros a los miskitu sin mezcla africana que, a partir del siglo XVIII, se van a reubicar en el litoral Sur del Atlántico.

35 Ibídem.

36 Ibídem.

37 AGI, Guatemala, 297, 50-61, "Informe de fray de la Concepción."

38 "Carta de la Audiencia de Guatemala sobre los establecimientos de los ingleses en la Costa, 1704" en Colección de documentos referentes a la historia colonial de Nicaragua, Managua, 1992, pág. 5.

39 Asentamientos de este tipo fueron formados por grupos mezclados de indios y esclavos cimarrones, como, por ejemplo, los indios seminoles, los ladino-bozales de Cuba, los indios caribes de St. Vicent o los maroons de Jamaica.

40 García, Claudia: The Making of the Miskitu People of Nicaragua. The Social Construction of Ethnic Identity, Acta Universitatis Upsaliensis, Uppsala, 1996. 
Mientras que los que residen en la zona circundante a Cabo Gracias a Dios son conocidos, indistintamente, como zambos o como mulatos, aunque ambas categorías implican cosas diferentes.

El proceso de hibridación va a continuar hasta el siglo XX y, por lo tanto, es necesario analizarlo, aunque sea brevemente. La voluntad a unirse con individuos no miskitu inicia el proceso de diferenciación de los bawhikas de los demás subgrupos de indios mayagnas (twahkaulwa, panamaka, kukra, yusku, prinzu, boa, silan y ku) y da origen a la emergencia de los miskitu. Las uniones mixtas ratifican, además, la alianza económica entre los ingleses y los miskitu y sientan la base para la construcción social de la identidad de los segundos. La relación entre los "mulatos miskitu" y los piratas parece haber sido más estrecha que la que los "indios puros" mantienen con aquéllos. Lo que no es extraño ya que los mulatos tienen una madre mestiza de africano con indio y un padre europeo. Un bucanero señala que los hombres mulatos asisten a los bucaneros y a los piratas, y las mujeres mulatas les ofrecen sus favores sexuales y domésti$\cos ^{41}$ De esta manera la hibridación del grupo permite afianzar las alianzas y asegurar a los ingleses su lealtad. No es ésta una situación única, algo parecido se registra durante este mismo período en la Costa de Guinea. Allí la interacción entre los europeos y los africanos asume diferentes formas, entre las que hay que destacar las uniones mixtas entre los colonos y comerciantes portugueses y las mujeres africanas. Como producto de este mestizaje aparece en el escenario local una casta de mulatos que, como en el caso de los miskitu, se va a convertir en el estrato social aliado de los europeos al desempeñar el papel de intermediarios entre las poblaciones nativas y los europeos. ${ }^{42}$

La adopción por los miskitu de individuos de diferentes orígenes (y con diferentes lenguas) es uno de los factores decisivos que promociona los intercambios interculturales. El hecho de que los individuos que llegan a la región no representen oficialmente a ningún poder colonial permite que los cambios se den en ambos sentidos, afectando tanto a la sociedad nativa como a la de los recién llegados. Los africanos y los europeos que se integran a los miskitu se encuentran alejados de los otros miembros de su propia sociedad y, por eso, tienden a ajustarse a las pautas tradicionales de los

41 De Lussan, Raveneau: Raveneau de Lussan, a Buccaneer of the Spanish Main and Early French Filibuster of the Pacific, a Translation into English of his Journal of a Voyage into the South Seas, The Arthur Clark Company, Cleveland, 1930, págs 286-287.

42 Thompson: African Diaspora ..., pág. 95. 
miskitu. Esto no hubiera sido posible de haberse tratado de agentes coloniales, obligados a responsabilizarse de su conducta ante las autoridades de la metrópoli. En este último caso las distinciones de raza serían determinantes del papel socialmente aceptado para unos y otros. ${ }^{43}$ Pero la autonomía, que caracteriza desde un comienzo la relación entre estos hombres no miskitu y los miskitu, promueve la construcción de una identidad con múltiples referentes. A su vez, de forma independiente de que sean identificados por los otros como "indios puros", "zambos" o "mulatos", los miskitu comienzan a reconocerse como parte de una misma colectividad por compartir una misma lengua.

\section{La consolidación del grupo}

Durante el siglo XVIII la sociedad miskitu se ve forzada a realizar diversos ajustes para dar respuesta a las necesidades del nuevo orden. Mi argumento es que los miskitu responden a los cambios sociales con estrategias que les permita asegurarse un beneficio material.

La creación del reino, a finales del siglo XVII, implica un cambio en el orden igualitario inicial de la sociedad miskitu. En 1720 a la figura central del rey zambo se suma la de otros dos jefes que se le subordinan: un gobernador indio y un general zambo. A estos se va a agregar veinte años después, en 1740, un tercero: el almirante indio. Hay, además, otros cargos como el de príncipe, quien normalmente es un pariente cercano del rey $\mathrm{y}$, por lo tanto, zambo.

Se especula que el título de capitán hubiera sido introducido inicialmente por los piratas para designar al jefe militar de cada aldea. ${ }^{44} \mathrm{~A}$ partir del siglo XVIII existe la posibilidad para los capitanes de ascender a general. Y, aunque como capitán se nombra indistintamente tanto a indios como a zambos, desde 1774 sólo los capitanes zambos son beneficiados con los regalos que el rey recibe de los ingleses. ${ }^{45}$

Entre los zambos, al menos dos individuos son nombrados "duque" y, a partir de mediados de siglo, a otros se les nombra "mayor" o "coronel". En todos los casos se trata de hombres de confianza del rey.

43 Banton, Michael: Race Relations, Tavistock Publications, London, 1967, pág. 72.

44 Romero Vargas, Germán: Las sociedades del Atlántico..., pág. 211.

45 Ibídem, pág. 213. 
Uno de los comerciantes ingleses de Bluefields señala que aunque los miskitu se consideran un pueblo único constituyen, en realidad, una unión de pueblos autónomos. ${ }^{46}$ Se trata de parcialidades claramente definidas en base a criterios étnicos y espaciales. La del rey zambo, que tiene autoridad sobre los zambos y otros indios no miskitu, se extiende entre Sandy Bay (lugar de residencia del rey) y el cabo Camerón. Allí comienza la del general zambo, que igualmente controla a los pueblos zambos e indios no miskitu que residen entre este punto y el Cabo Gracias a Dios. Mientras que el distrito del gobernador indio abarca desde Sandy Bay a Bragman Bluff, y el del almirante la región que se localiza hacia el Sur de Bragman Bluff. Ambos, gobernador y almirante, mandan únicamente sobre los "indios puros", pero deben obediencia al rey zambo.

Por una parte, puede decirse que la subdivisión del territorio en parcialidades bajo la autoridad de un jefe zambo o "indio puro" es una muestra de la adaptabilidad de la sociedad miskitu. La existencia de territorios claramente definidos, controlados por un líder zambo o indio que depende del rey, facilita la interacción con los ingleses. Por otra, si bien los miskitu incorporan nombramientos por escrito y el uso de títulos europeos, su sociedad continúa organizándose en base a las redes de parentesco. Tanto en el caso del rey como del general, del gobernador y del almirante se sigue el modelo de sucesión de las jefaturas tradicionales, en el que los cargos son hereditarios por línea paterna. Así que, aunque los miskitu soliciten los nombramientos para estos cargos a las autoridades inglesas de Jamaica o de Belice, éstas sólo validan una elección previa del grupo, que se basa en un modelo de conducta tradicional.

\section{Adaptaciones económicas}

Durante el período de gobierno del rey zambo Edward (1739-1755) se transforman las aldeas de Black River y de Bluefields en los centros más importantes de comercio ilegal de la región. ${ }^{47}$ Black River, poblado que en 1732 fundara William Pitt, se va a convertir en la "punta de lanza de la

46 Hodgson, Robert Jr.: Some Account of the Mosquito Territory, contained in a memoir written in 1757, William Blackwood, Edinburgh, 1822.

47 Archivo Histórico Nacional, Estado, 53, 24, "Virrey de Santa Fé solicita copia de varios tratados", Santa Fé, 19 de abril de 1804. Archivo General de Simancas, Secretaría de Guerra 6946, 2, "Pacificación de indios moscos", Cartagena, 12 de julio de 1787. 
penetración inglesa en el territorio de la Audiencia hasta 1763". ${ }^{48}$ Allí llegan los productos ingleses: hierro en barras, ron, cuerdas, utensilios de hierro, sal, loza, jabón, madera para construcción de casas, aceite, paños y telas de diversas calidades, armas de fuego. Y desde allí se abastece a los barcos de concha de tortuga, zarzaparrilla, caoba, oro, plata, mulas, algodón, cuero de venado y de res, cacao y reses.

Otra figura clave para el desarrollo del comercio ilegal es Henry Corrin quien, gracias a la colaboración mantenida con los indios ulvas, logra establecer una red de intercambio de productos entre Bluefields y la zona que se extiende entre Matagalpa y Acoyapa.

Pero quien logra concentrar en sus manos la mayor parte del comercio local es Robert Hodgson, el hijo del primer superintendente de la Costa de Mosquitos, casado con Isabel Pitt, hija de William Pitt y de una española que aquel lograra rescatar del cautiverio entre los miskitu. Hodgson hijo pertenece a la segunda de tres generaciones de Hodgson blancos residentes en la Costa de Mosquitos, y cuyos numerosos descendientes ilegítimos (mulatos) junto con sus esclavos van a dar origen a la futura población creole de Bluefields, Laguna de Perlas y Corn Island. ${ }^{49}$

Robert Hodgson hijo da trabajo en su establecimiento de Bluefields a otros europeos y cuenta con, por lo menos, doscientos esclavos negros. Dispone, además, de un bergantín, una balandra y una fragata con las que transporta los productos locales a Jamaica, a las colonias de Norteamérica y a Gran Bretaña, a la vez que abastece la región de productos manufacturados europeos.

A mediados de siglo, los colonos ingleses que residen en la Costa de Mosquitos piden protección a las autoridades de Jamaica, aduciendo temer un ataque de parte de los miskitu. El intercambio de correspondencia entre Jamaica y Londres da testimonio de los rumores sobre posibles alzamientos que sacuden la región y de la inquietud que esta situación suscita en los colonos ingleses..$^{50}$

Las autoridades de Jamaica toman la decisión de establecer en Black River la sede de una superintendencia en 1749. El poder político de los

48 Romero Vargas: Las sociedades..., pág. 87. AHN, Consejo, 20969-20970, “Asuntos seguidos sobre el recurso hecho a esta Real Audiencia por Don Francisco de Thoves y Don Domingo de Azaña Zalazar, oficiales de las Cajas Reales de la ciudad de Comayagua, por haberlos puesto preso Don Pedro Truco", Guatemala, 19 de agosto de 1750.

49 Romero Vargas: Las sociedades..., págs. 104-105.

50 British Public Record Office, Colonial Office, 137/35, "Letter from Richard Jones", Jamaica, 8 de agosto de 1768 . 
individuos que ejercen este cargo (entre 1749 y 1787), que les ha sido delegado por el gobernador de Jamaica con el fin de garantizar la seguridad de los colonos ingleses, es respetado por los miskitu con reservas. Así lo confirma el viaje que realiza a Londres un grupo de miskitu a instancias del rey zambo para protestar por la postura del primer superintendente de la Costa de Mosquitos acerca de la esclavitud indígena. ${ }^{51}$

Durante este período se consolida el rol de intermediarios de los zambos entre los ingleses y los demás habitantes del área. ${ }^{52}$ Los ingleses entregan productos no tradicionales al rey zambo y éste los distribuye entre sus jefes principales. La redistribución es una de las formas que le permite a un jefe asegurarse la estima de los miembros de su grupo. ${ }^{53}$ Los jefes deben ser generosos con su pueblo, dar para recibir, sin poner en peligro el complejo equilibrio entre prestaciones y privilegios, en el que se basa la relación con su gente..$^{54} \mathrm{La}$ redistribución es, entonces, uno de los atributos que reviste de poder al rey zambo y que le asegura ciertos privilegios, como el de tener muchas esposas. Le garantiza, a la vez, recibir los favores o servicios de los miskitu. Si bien no se sabe con exactitud de qué forma los productos entregados por los ingleses benefician a los zambos e indios de las comunidades, podemos aventurar, a modo de hipótesis, que la mayor parte de éstos quedan en manos de los jefes principales. Este razonamiento se apoya en el monto reducido de dichos productos, así como en ciertas descripciones de viajeros del siglo XVIII que dan testimonio, por ejemplo, del uso de trajes y sombreros europeos únicamente por los jefes principales. Y las frecuentes menciones acerca de que éstos actúan de una cierta manera porque la consideran "moda inglesa". ${ }^{55} \mathrm{Se}$ consolida así una clase dirigente cuya característica principal es la hibridación racial y cultural.

Pero si la apropiación de productos no tradicionales fuera un privilegio exclusivo de los líderes se originarían conflictos internos difíciles de

51 BPRO, Colonial Office, 137/64, "Letter from Thomas Trelawny to the Earl of Hillsborough", Black River, 25 de febrero de 1769.

52 Noveck, Daniel: "Class, Culture, and the Miskito Indians", Dialectical Anthropology, 13, Amsterdam, 1988, págs 20-24.

53 Carneiro, Robert L.: "The Chiefdom: Precursor of the State" en Grant, Jones y Robert R. (editores): The Transition to Statehood in the New World, University Press, Cambridge, 1981, pág. 58. pág. 208.

54 Levi-Strauss, Claude: Spillror av paradiset (Tristes Tropiques) (1955), Arkiv, Lund, 2000 ,

55 Young, Thomas: Narrative of a Residence on the Mosquito Shore, Smith, Elder, and Co, London, 1842, pág. 33, y Roberts, Orlando W: Narrative of Voyages and Excursions on the East Coast and the Interior of Central America, Gainesville, Florida, 1818 y 1927, pág. 114. 
solucionar. Con el fin de evitar que esto suceda se abren vías alternativas para que zambos e indios puedan acceder a dichos productos. La primera y principal de estas vías es el ataque organizado y sistemático a los poblados españoles. Estas incursiones permiten tanto a los zambos como a los indios obtener un botín, para intercambiar por otros productos a los comerciantes ingleses. Pero el éxito de estos ataques depende, en gran medida, de que las fuerzas miskitu cuenten con pertrechos militares. Por eso las armas de fuego van a alcanzar una gran difusión entre los miskitu y, por eso, se suceden los pedidos de exportación de armas y municiones destinadas a ser vendidas a zambos e indios de la Costa de Mosquitos. ${ }^{56}$

En 1711 se afirma que la población total de miskitu alcanza los 5 ó 6 mil individuos, de los cuales 900 ó 1000 son hombres capaces de tomar armas. En esta cifra se incluyen 500 "esforzados y denodados corsarios". ${ }^{57}$ Mientras que algunos años después, en 1739, se considera que son 2.000 los miskitu armados. Y se asegura que "todos los zambos mosquitos están hechos al manejo de las armas y proveídos con abundancia así de las de fuego como de las blancas". ${ }^{58}$

No es sólo a través del intercambio como los miskitu obtienen armas sino, también, por medio de la apropiación forzosa. Se informa, por ejemplo, que en 1757 los zambos apresaron una balandra española en la que se envíaban a Costa Rica 500 fusiles, pólvora y municiones. De esta manera, el armamento destinado inicialmente a que los habitantes del Valle de Matina se defiendan de los miskitu acaba sirviendo para aumentar la capacidad de agresión de estos últimos. ${ }^{59}$ Para 1780 las autoridades españolas evalúan la población de zambos en 6.000 individuos, y se afirma que la "cantidad de hombres capaces de tomar armas, nadie puede saberlo, pero es constante que componen un extraordinario número." ${ }^{60} \mathrm{Se}$ calcula, además, que los indios son unos 3.000, y que de ellos 600 portan armas. ${ }^{61}$

56 Romero Vargas: Las sociedades del ..., págs. 89-91.

57 "Informe de Fray Benito Garret y Arboli, obispo de Nicaragua, sobre los mosquitos y el modo de reducirlos", en De Peralta: Costa Rica y ..., pág. 59.

58 "Consulta de Don Francisco Campo de Arve al Consejo de Indias, 8 de julio de 1739", en Ibídem, pág. 115.

59 "Carta de Don Alonso de Arcos Moreno, 25 de mayo de 1757”, Ibídem, págs. 150-151.

60 "Varias noticias del río San Juan, Yslas adyacentes de la Costa de Mosquitos, provincias y partidos que tiene el Reyno de Goatemala años 1791 a 1804”, en Relaciones históricas y geográficas de América Central, Madrid, 1908, págs. 287-328.

61 Ibídem. 


\section{Las incursiones armadas}

A partir del siglo XVIII los asaltos de los miskitu contra los poblados españoles se vuelven asiduos y pasan a tener un objetivo bien definido: asegurar un beneficio material al grupo. En 1701, 1707, 1708 y 1711 atacan las plantaciones de Costa Rica para llevarse esclavos y la producción de cacao. En 1705 toman Muy Muy Viejo y durante tres años seguidos (1708, 1709 y 1710) Chontales; en 1699 atacan Nueva Segovia y vuelven a hacerlo en 1701 y en 1704. Se registran también incursiones de miskitu a las poblaciones hondureñas del este del río Ulúa en 1702, y en 1704 a las aldeas indígenas para hacer prisioneros, luego vendidos a los ingleses como esclavos, y apropiarse de productos locales, los cuales intercambiar por otros de manufactura europea.

Otro cambio en la actividad militar es que ya no se trata de individuos o grupos de miskitu que acompañan a los piratas en sus expediciones de piratería. Ahora la relación se invierte, la iniciativa de atacar la toman los propios miskitu aunque, a veces, lo hagan en colaboración con los ingleses. ${ }^{62}$ Es, únicamente, durante los conflictos entre Inglaterra y España cuando los ingleses dirigen las incursiones armadas, mientras que en los períodos en los que reina la paz entre ambas potencias son los miskitu quienes atacan, aunque lleven en su ayuda a individuos británicos. ${ }^{63} \mathrm{~A}$ esto se refiere el gobernador de Nicaragua, en un informe de 1759, donde afirma:

\footnotetext{
"no puedo referir sin dolor las hostilidades e invasiones que ha experimentado esta provincia en este siglo, por los indios zambos mosquitos, por sí en tiempos de paz y tripulados por los ingleses en el de guerra, por el año 1709 y 1710 , saquearon por tres veces el partido de Chontales, robando y talando sus haciendas, y llevándose diferentes familias prisioneras. ${ }^{64}$
}

Otra transformación en las actividades militares es que los miskitu se ofrecen como ejército a disponer por los británicos ante cualquier eventualidad en su área de influencia. El primer acuerdo oficial en este sentido lo firma el segundo de los reyes zambos, Jeremy II (1720-1729), con el gobernador de Jamaica y el objetivo del mismo es reprimir una rebelión maroon

62 Ayón ,Tomás: Historia de Nicaragua, Managua, 1956, págs. 194-95.

63 Ibídem, págs. 194-195.

64 García Pelaez, Francisco de Paula: Memorias para el antiguo reino de Guatemala. Tipografía de L. Luna, Guatemala, 1851 y 1943, tomo II. 
en la isla en $1722 .{ }^{65}$ Posteriormente, fuerzas miskitu viajan a Jamaica con este mismo fin en otras dos ocasiones. Y más tarde, el rey zambo se ofrece también a enviar hombres armados para ayudar a contener las revueltas de Norteamérica.

Sin embargo, este servicio prestado por los miskitu a los ingleses se realiza para obtener una ganancia material. Por eso los miskitu condicionan su ayuda militar a la firma de un acuerdo previo, en el cual se estipula el pago que zambos e indios recibirán, así como el subsidio de la viuda, en caso de que algún miskitu muera en el combate, y la parte del botín que va a corresponder a cada hombre de acuerdo a su prestación. ${ }^{66}$ Dicho acuerdo reglamenta, entonces, la colaboración militar entre los miskitu y los ingleses y, a la vez, la formaliza como una segunda vía para adquirir productos no tradicionales.

\section{La interacción con los españoles (1787-1800)}

En 1783 Inglaterra se compromete con España a que los 569 colonos ingleses que residen en la región, junto con sus 1.763 esclavos, deben abandonar el territorio del reino miskitu en un lapso de dieciocho meses. A cambio de ello España les permite establecerse en la zona comprendida por los ríos Walix, Hondo y Nuevo, en la provincia de Yucatán. ${ }^{67}$ Para hacer efectiva la evacuación de los colonos ingleses las autoridades españolas solicitan datos sobre cuántos establecimientos poseen en la región, que, al parecer, suman unos veinticinco entre el escudo de Veragua y Honduras. ${ }^{68}$

Ese mismo año las autoridades españolas proponen combatir a los miskitu hasta lograr "su total destrucción". ${ }^{69}$ Poco tiempo después, sin embargo, y quizás debido a los problemas económicos que la colonia debe enfrentar, se recomienda "suspender las hostilidades contra los mosquitos

65 Thompson: African Diaspora, pág. 280, y Olien, Michael: "The Miskito Kings and the Line of Succession", Journal of Anthropological Research, Albuquerque, 1983, pág. 205. pág. 156.

66 Uring, Nathaniel: Voyages and Travels of Captain Nathaniel (1726), Cassell, London, 1928,

67 "Reales órdenes sobre la evacuación por los ingleses de la Costa de Mosquitos, 25 de agosto de 1783", en De Peralta: Costa Rica y...., págs. 213-217.

68 "Informe del Virrey de Santa Fe al Secretario de Estado sobre establecimientos ingleses, 21 de marzo de 1784", Ibídem, págs. 224-230.

69 "Real Orden sobre la destrucción de los mosquitos a sangre y fuego, San Idelfonso 4 de agosto de 1784”, Ibídem, pág. 228. 
e ingleses" mientras duren las negociaciones entre España e Inglaterra. ${ }^{70}$ Un año después, en 1786, se descartan los planes para destruir a los miskitu. Ahora se habla, por el contrario, de que es necesario ganarse la buena voluntad de los mismos por medio de "agasajos, regalos y expresiones de sinceridad y benevolencia". ${ }^{71} \mathrm{Y}$ para implementar esta última propuesta se autoriza a las autoridades locales a comprar por cuenta de la Real Hacienda "algunos de los géneros que (sean) más a gusto (de los miskitu), exceptuadas las armas, y en la calidad y cantidad acostumbrada por los ingleses". ${ }^{72}$ La política española de dar continuidad a la entrega de regalos a los miskitu al estilo inglés se debe, precisamente, a una recomendación de Robert Hodgson hijo. Otro comerciante inglés, Colville Crains, evaluará en 300 libras esterlinas anuales el costo de los regalos que los miskitu reciben de los ingleses. ${ }^{73}$

La retirada de los colonos ingleses se efectúa en 1787, con excepción de Robert Hodgson hijo, a quien las autoridades españolas le permiten permanecer en la región, a condición de que colabore con ellas. Éste les propone implementar una política de "dividir para gobernar". Según el comerciante inglés resulta necesario enfrentar a los zambos con los indios, y una de las formas de lograrlo es beneficiar con productos sólo a los indios para crear descontento entre los zambos. Y una vez establecida la discordia entre ambos, agudizarla con ayuda de los indios twahkas, con quienes los españoles mantienen trato y a quienes los zambos persiguen para esclavizar. ${ }^{74}$

La propuesta de Hodgson de "dividir para gobernar" se fundamenta, seguramente, en el conocimiento que éste tiene de otros conflictos anteriores entre zambos e indios, que no fueron independientes de los intereses de España. Durante el gobierno del rey zambo George I (1755-1776), por ejemplo, los españoles aumentan las diferencias entre zambos e indios al brindar su apoyo al almirante indio Dilson, lo que conduce a éste a enfren-

70 "Reales Ordenes de El Pardo, 20 de enero de 1785, sobre que se suspenderán las hostilidades contra los mosquitos e ingleses establecidos en su costa, mientras duran las negociaciones con la Gran Bretaña y copias de las resoluciones del Rey comunicadas al ministro de S.M. británico en Madrid", en De Peralta: Costa Rica y..., págs. 242-247.

71 "Reales órdenes sobre evacuación por los ingleses de la Costa de Mosquitos, San Idelfonso, 21 de septiembre de 1786", Ibídem, págs. 254-259.

72 Ibídem.

73 AGS, Secretaría de Guerra, 6949, 14, "Costo establecimientos en Costa de Mosquitos", Guatemala, 24 de febrero de 1797.

74 AHN, Estado 4227, "Carta dirigida a Don Bernardo del Campo por el Conde Floridablanca", Londres, 29 de enero de 1788, "Informe sobre Roberto Hodgson”, Londres, 12 de septiembre de 1785 . 
tarse con los líderes zambos y, posiblemente, ocasiona su repentina e inexplicable muerte en marzo de $1770 .{ }^{75}$

Los miskitu no se oponen a tratar con los españoles siempre que obtengan de ello un beneficio material. Una de las primeras negociaciones entre los españoles y los zambos e indios, luego de la evacuación de la población inglesa, es para acordar la devolución de los cautivos. Aquí prevalece, también, el interés de los miskitu por obtener una ganancia ya que se niegan a devolver a esos prisioneros si no reciben, a cambio, una compensación en productos de parte de los españoles. ${ }^{76}$

En ocasiones anteriores los miskitu han tomado la iniciativa de contactar con los españoles. En 1739, por ejemplo, el rey zambo les propone un tratado de paz y de comercio con España. ${ }^{77}$ Y en otra ocasión, en abril de 1789, varias piraguas de zambos miskitu se acercan a Matina para exigirle al gobernador que les dé regalos. Y éste, luego de consultar con el gobernador intendente de Nicaragua, les entrega productos por valor de 807 pesos con 6 reales. ${ }^{78}$ A partir de entonces, las visitas de los zambos miskitu con la misma demanda se repiten y siempre son atendidos con deferencia por el gobernador. Pero las autoridades locales se enfrentan, muchas veces, con dificultades para abastecer a los miskitu y, cuando les resulta imposible satisfacer sus pedidos, comienzan a correr rumores de que el rey zambo planea atacar los poblados españoles. ${ }^{79}$ A ello se debe la propuesta, del 5 de agosto de 1789, de autorizar una especie de comercio libre en la región con el fin de paliar la escasez de aquellos productos que los miskitu desean. ${ }^{80}$ Posteriormente, una real orden del 18 de junio de 1791 va a reglamentar la entrega periódica de regalos a los miskitu. ${ }^{81}$ Aunque, más tarde, con el interés de reducir el presupuesto, se les llega a ofrecer a los jefes principales miskitu una compensación económica que oscila entre los 400 y los 900 pesos anuales, ${ }^{82}$ los miski-

75 Olien: “The Miskito Kings..”, pág. 121.

76 AGS, Secretaría de Guerra, 6947, 2, "Evacuación de ingleses Costa de Mosquitos", "Carta de Marqués de Sonora al Presidente de Guatemala", Guatemala, 15 de mayo de 1787.

77 "Consulta de Don Francisco Campo de Arve al Consejo de Indias, 8 de julio de 1739" en De Peralta: Costa Rica y ...., págs 98-115.

78 Gámez, José Dolores: Historia de la Costa de Mosquitos, Talleres Nacionales, Managua, 1939, págs. $164-165$

79 AGI, Guatemala, 697, "Carta de Estanchería a Valdés", Guatemala, 18 de junio de 1789.

80 AHN, Estado 4227, "Problemas económicos para sostener establecimientos en América (Dictamen sobre establecimientos ingleses en Costa de Mosquitos)", San Lorenzo, 26 de noviembre de 1775 .

81 Sorsby: "Spanish Colonization..", pág. 150.

82 AGS, Secretaría de Guerra, 6951, 3 “Atracción de indios Moscos”, Guatemala, 2 de enero de 1797 . 
tu se muestran desinteresados en recibir este pago en moneda y manifiestan preferir la entrega de productos al estilo inglés. ${ }^{83}$

La sociedad miskitu es una sociedad abierta al exterior y la adquisición de artículos importados, de difícil acceso en la colonia, ha llegado a convertirse en una necesidad cultural y en la meta que guía la conducta social del grupo. Las autoridades españolas locales recomiendan que se les entreguen productos (herramientas, armas, municiones aguardiente, géneros, ropas, sombreros y calzados) de buena calidad, ya que los miskitu están acostumbrados a los que les dan los ingleses, que provienen o bien de Jamaica o bien de Europa y que, por eso, no es raro que rechacen por "toscos y pesados" los que los españoles les hacen llegar de Cuba o de Cartagena. ${ }^{84}$

Los miskitu manifiestan que la entrega de regalos y los intercambios de productos deben regirse por reglas justas; idea que, según ellos mismos, Robert Hodgson hijo no comparte. El comerciante inglés no cuenta con la simpatía de los indios por lo que uno de sus jefes, afirmando que Hodgson los trata en forma injusta, ataca su establecimiento y decomisa sus productos. Hodgson salva la vida gracias a la intervención de su mujer, a quien los miskitu respetan por su relación con William Pytt, pero es expulsado junto con su familia de la región..$^{85}$

\section{La colonización española (1787-1800)}

Luego del alejamiento de los ingleses, España se propone establecer poblados fijos en Black River, Cabo Gracias a Dios, Bluefields y Río San Juan con 992 colonos provenientes de Asturias y Galicia y otros 306 de Canarias ${ }^{86} \mathrm{Y}$ como se considera que "las faenas de la agricultura en aquel cálido clima y bajo de los ardores del sol (son) insuperables a los blancos"

83 Ibídem.

84 "Relación del reconocimiento geométrico y político de la Costa de Mosquitos, desde el establecimiento de Cabo de Gracias a Dios hasta el de Blewfields, practicado por el ingeniero ordinario Don Antonio Porta Costas, en virtud de orden del M.I.S. Presidente don José de Estachería, año 1790", en Relaciones históricas y geográficas de América Central, Madrid, 1908, págs. 257-283.

85 AGS, Secretaría de Guerra, 6950, 6, "Diario de Félix Jons sobre la Costa de Mosquitos", Guatemala, 7 de agosto de 1796.

86 Gámez: Historia de la..., pág. 143. AGS, Secretaría de Guerra, 6948, 2 y 13, "Repoblación Costa de Mosquitos", San Cruz de Tenerife, 13 de diciembre de 1788, AGS, Secretaría de Guerra, 6934, 38, "Artillería Costa de Mosquitos", Guatemala 31 de agosto de 1792, AGS, Secretaría de Guerra, 6949, 14, "Costo anual de establecimientos en Mosquitos", Guatemala, 24 de febrero de 1790. 
se aprueba la entrada de un contingente de africanos, ya que sólo "los negros" son aptos para tales tareas. ${ }^{87}$ Estos africanos, ex combatientes de la sofocada revolución de Santo Domingo en 1791, llegan en dos contingentes: el primero es un grupo deportado por el entonces gobernador francés de la isla a Cayo Inglés, localizado a 7 leguas de Belice, desde donde se dirige a la Costa de Mosquitos; ${ }^{88}$ el segundo contingente de africanos llega de Cádiz. Se trata de 142 individuos cuyo traslado se aprueba por real orden del 29 de octubre de $1796 .{ }^{89}$

$\mathrm{Al}$ año de su llegada, en 1797, las epidemias han diezmado a los colonos españoles, mientras que los africanos comienzan a mezclarse con los zambos. La población británica, por su parte, va en aumento y llegará a superar a la existente antes de la evacuación..$^{90}$

Los planes españoles cuentan con el apoyo del gobernador indio Briton, quien se ha convertido al catolicismo para poder casarse con una de sus cautivas españolas; algo que el rey zambo desaprueba. ${ }^{91}$ Por lo tanto, al recomendar Hogdson agudizar la discordia entre zambos e indios está en conocimiento, indudablemente, del malestar que existe entre ambos. Y aunque del material del que dispongo no trasciende claramente hasta qué punto las intenciones de los españoles se concretaron en hechos, lo cierto es que el conflicto zambo-indio no puede verse con independencia de la interacción que los miskitu sostuvieron con las autoridades españolas.

El gobernador indio facilita la entrada de los frailes franciscanos a las áreas bajo su dominio, lo que lo conduce a un enfrentamiento abierto con el rey zambo. El almirante Alparis, sobrino de Briton, acaba por desconocer la autoridad de éste y, con la ayuda del rey zambo, lo detiene y lo lleva ante una junta de jefes principales zambos e indios, en la que se le condena a morir por traición. Este suceso marca el destino final de la colonización española, que no puede subsistir sin el apoyo de los miskitu, especialmente cuando escasean los recursos económicos, la mayoría de los colonos ha fallecido y los soldados desertan para no ser enviados a la región. ${ }^{92}$

87 Ibídem.

88 Gámez: Historia de la ..., pág.162.

89 AGS, Secretaria de Guerra, 7161, 24, "Negros auxiliares, pases y empleos", Santo Domingo, 3 de noviembre de 1795 . zo de 1797

90 AGS, Secretaría de Guerra, 6951, "Carta del fiscal de Guatemala", Guatemala, 11 de mar-

91 García, Claudia: "Interacción étnica y diplomacia de fronteras en el reino miskitu a fines del siglo XVIII", Anuario de Estudios Americanos, LVI-1, Sevilla, 1999, págs. 95-121.

92 AGS, Secretaría de Guerra, 6949, 14, "Costo establecimientos en Costa de Mosquitos", Guatemala, 24 de febrero de 1790 . 
Durante la última década del siglo XVIII se suceden las luchas armadas y las ejecuciones de líderes indios por órdenes del rey zambo. ${ }^{93} \mathrm{Y}$, aunque es exagerada la afirmación de que los "indios puros" son totalmente eliminados por los zambos, el siglo XIX se va a caracterizar por la hegemonía zamba. ${ }^{94}$

En 1798 corren rumores de que el rey zambo George II, con el apoyo del superintendente de Belice, planea atacar Trujillo. ${ }^{95}$ Lo que, sin embargo, no llega a concretarse. Pero dos años después el rey zambo toma el poblado y el fuerte de Black River y, sin encontrar mayor resistencia, desaloja a los españoles y libera a los esclavos. ${ }^{96}$ Para 1800 no va a haber colonos españoles en la Costa de Mosquitos. Y a pesar de que el rey zambo es ajusticiado ese mismo año por los zambos de su parcialidad, la dinastía miskitu contará aún con ocho reyes zambos más. ${ }^{97} \mathrm{Si}$ bien los españoles continuan con su política de entregar regalos a los miskitu, se recomienda que éstos deben "(suministrarse sólo) cuando se (considere) absolutamente indispensable para evitar mayores inconvenientes....(pero sin guardar) un período determinado ...para no hacer (de ello) una costumbre".$^{98}$

El modelo de interacción con los europeos y los demás grupos indígenas del territorio centroamericano que, una vez conformado, se mantiene prácticamente inalterable durante el siglo XVIII, va a transformarse durante el XIX como consecuencia de los cambios en la economía mundial. Al tiempo que desaparece el comercio de esclavos cesan las incursiones armadas de los miskitu a las aldeas de los indios vecinos para hacer cautivos. Y esta práctica es reemplazada con la obligación de tributar al rey zambo. Además, y debido a que empresas extranjeras comienzan a invertir a gran escala en la región, se produce un aumento de la demanda de mano de obra libre y asalariada, lo que conlleva a que la adquisición de productos no tradicionales se convierta en una opción individual.

93 AGS, Secretaría de Guerra, 6934, 50, "Dos cartas del presidente que no tuvieron curso", Guatemala, 24 de febrero de 1792. AGS, Secretaría de Guerra, 6950, 6, "Diario de Félix Jons sobre la Costa de Mosquitos", Guatemala, 7 de agosto de 1796.

94 Wright, John: Memoir of the Mosquito Territory, J. Hatchard, London, 1808.

95 AGS, Secretaría de Guerra, 6951, "Carta de José Domás Valle a Don Miguel José de Azanza", Guatemala, 2 de enero de 1797.

96 AGI, Guatemala, 481, "Informe de Echeverría", Guatemala, 19 de septiembre de 1800.

97 Museo Naval de Madrid, 570, 426, "Informe del intendente de Nicaragua a Domás y Valle", Guatemala, 5 marzo de 1800.

98 "Real Orden de Barcelona sobre la organización militar del país y la defensa de la Costa de Mosquitos, 5 de octubre de 1802”, en De Peralta: Costa Rica y..., págs. 337-341. 